\title{
Toxic jellyfish in Thailand
}

\section{Hansa Premmaneesakul ${ }^{1}$, Pornchai Sithisarankul ${ }^{2}$}

${ }^{1}$ Naval Medical Department, Maritime Medicine Residency Training Centre, Thailand

${ }^{2}$ Department of Preventive and Social Medicine, Faculty of Medicine, Chulalongkorn University, Thailand

\begin{abstract}
Jellyfish stings are common in Thailand. Stings can range from mild skin irritation to severe systemic symptoms resulting in death. Jellyfish envenomation is becoming an important public health concern. The lethal box jellyfish and bluebottle jellyfish are found on the Gulf of Thailand and Andaman coasts, but there are still misconception and mismanagement of these types of severe stings. Prevention and awareness of jellyfish stings are important, as well as knowledge and first aid management of severe envenomation. Educational programmes should be provided to locals including school children, teachers, hotel and tour operators, and medical staff. This will greatly reduce the morbidity and mortality associated with fatal stings.
\end{abstract}

(Int Marit Health 2019; 70, 1: 22-26)

Key words: jellyfish, bites and stings, Chironex, Physalia, jellyfish venom

\section{INTRODUCTION}

Jellyfish envenomation is becoming an important public health concern in Thailand. Jellyfish stings range from mild skin irritation to severe systemic symptoms which can result in death. Worldwide, jellyfish are distributed across the subtropical or tropical waters of the Atlantic, Pacific, Asian, and Australian coasts. There are over 10,000 species of which about 100 are toxic to human beings [1].

Jellyfish are invertebrates belonging to the Phylum Cnidaria. There are four classes, namely Schiphozoa, Cubozoa, Hydrozoa, and Anthozoa. Schiphozoa are the most common type and considered "true jellyfish". This class contains Chrysaora and Pelagia which are common in Thailand, and stings can sometimes result in severe pain which requires treatment in the emergency departments from time to time. Cubozoa are the most lethal types, consisting of Chirodropidae and Carybdeidae. Hydrozoa are not considered true jellyfish, but are siphonophores, which include the Physalia species [2], such as the Physalia physalis (Portuguese manof-war), and Physalia utriculus (bluebottle/Pacific man-ofwar). Physalia can also cause deaths, though it is rare and symptoms are less severe than those caused by Cubozoa. Anthozoa are sea anemones and corals, some of which are classified as venomous.

Cubozoa are quite similar to the true jellyfish, but are boxlike, hence they are known as "box jellyfish". The or- der Chirodropidae consists of the multi-tentacled Chironex which is considered the most dangerous animal in the world, causing deaths within 2-10 min after being stung. There have been over 100 reported deaths from Chironex fleckeri. The smaller single-tentacled box jellyfish, carybdeids, include Carukia barnesi or the "Irukandji jellyfish", can also cause severe systemic symptoms known as the Irukandji syndrome [3], with 2 deaths reported in Australia [4, 5].

In 2008, the Toxic Jellyfish Network in Thailand was setup with collaboration from the Bureau of Epidemiology and experts from the Community Medicine Department, Faculty of Medicine, Chiang Mai University, with initial members including experts from universities in Australia and Divers Alert Network. The membership expanded to stakeholders such as resort or hotels managers or owners, divers, boat operators, and biologists to help gather information and implement education and prevention programs [6]. There were a total of 381 injuries and deaths from toxic jellyfish in Thailand from 2003 to 2018 (Fig. 1) [7].

Fatal stings can be handled with appropriate first aid and management and thus will reduce the morbidity and mortality. In Thailand, there are no lifeguards on public beaches; therefore, it is important that local population and bystanders know about the crucial steps in helping these victims. 


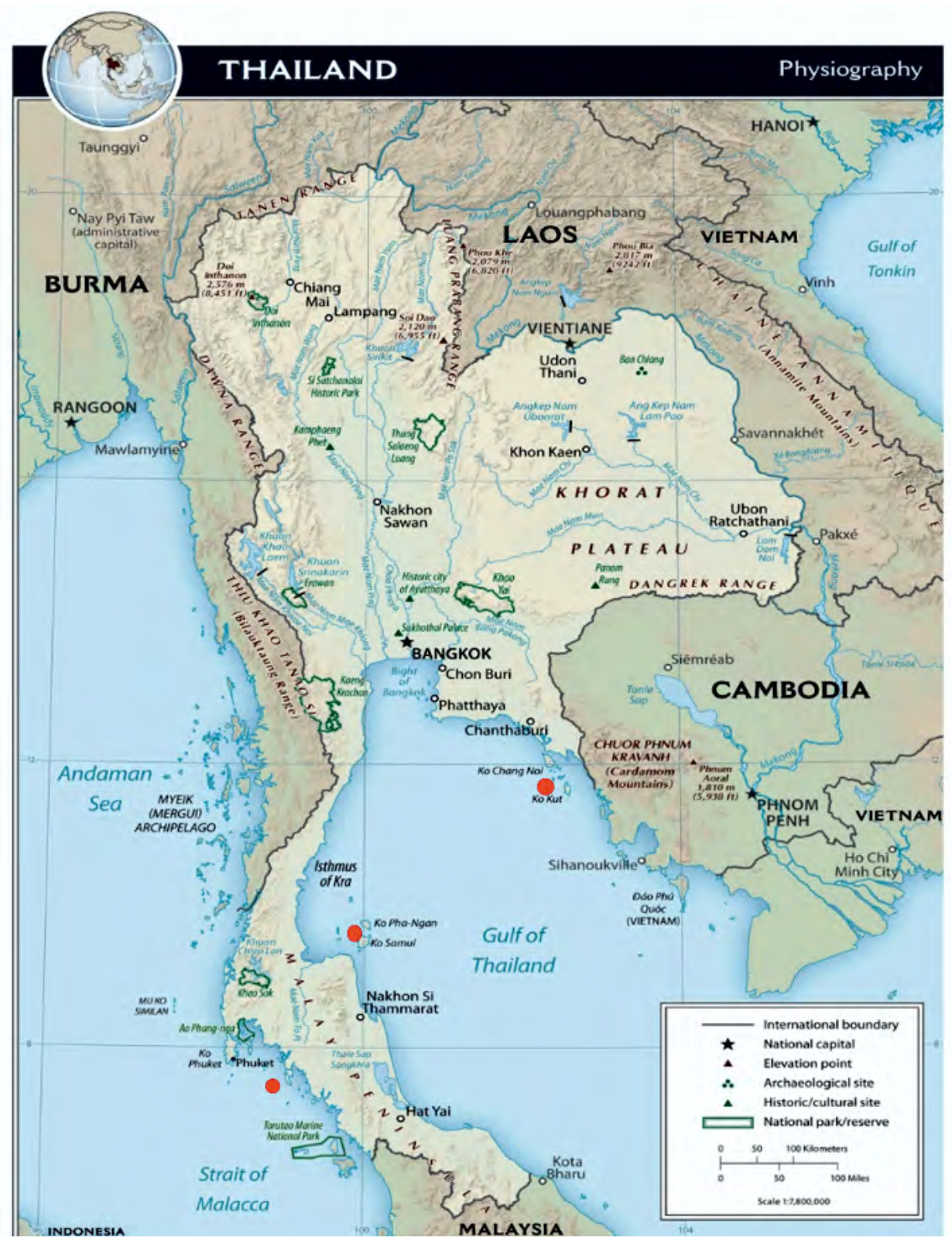

Figure 1. Reported fatalities on both coasts of Thailand (map from cia.gov)

\section{BOX JELLYFISH}

The three known species of multi-tentacled box jellyfish in Thailand are Chironex spp. A, Chironex indrasaksajiae (formerly Chironex spp. B), and Chironex spp. C. They are genetically different from the Australian Chironex fleckeri, but nevertheless are also lethal. Chironex have a white or translucent box-shaped bell, which can be as wide as $20 \mathrm{~cm}$. Four bundles of up to 15 translucent or bluish extensile tentacles stream out from 4 fleshy arms (pedalia) under the bell. Tentacles may reach up to $3 \mathrm{~m}$ and are covered with millions of stinging capsules or nematocysts, whereas the bell does not contain stinging capsules [8]. The severity of injury is related to the size of the jellyfish and extent of tentacle contact. Children are more prone to the toxic effects of this jellyfish, likely due to their body surface skin being thinner and having a lower body mass index $[1,9]$. The venom contains three main components, which is neurotoxin, cardiotoxin, and dermatonecrotic toxin [10]. When envenomation occurs, the victim will feel instantaneous extreme pain, causing them to leave the water. The stung area will develop characteristic ladder-like transverse bands or whip-like marks, which may result in necrosis and permanent scarring. Death can occur within minutes due to cardiorespiratory arrest.

The single-tentacle box jellyfish or carybdeids have one tentacle arising from each corner of their cubic-shaped bell. 
Carukia barnesi, the Irukandji, bells are about $12 \mathrm{~mm}$ wide and tentacles ranging from a few centimetres to up to $35 \mathrm{~cm}$ [8]. Nematocysts cover the bell and on the tentacles. Their bodies and tentacles are almost completely transparent. However, in Thailand, single-tentacle jellyfish that causes Irukandji-like syndrome are currently believed to be from Morbakka spp. A, Morbakka spp. B, and Morbakka spp. C. These species are usually found in deeper waters, but recently there have been more reports of injuries from these species closer to the shore [7]. Irukandji syndrome develops slightly slower than that caused by Chironex, usually within 5-40 min, the average being about $30 \mathrm{~min}$. The victim may or may not be aware of a sting, and can go unnoticed until the onset of symptoms, forcing the victim to leave the water. There could be mild erythema or no skin lesions at all. Symptoms consist of low back pain, muscle cramping, nausea, vomiting, coughing, difficulty in breathing, excessive sweating, and restlessness. This might lead to drowning if the victim had not left the water immediately [5]. Shivering, fever, tachycardia, and hypertension may develop. Pulmonary oedema and intracerebral haemorrhage may occur in severe cases [11]. This envenomation is believed to be caused by excess catecholamines and hyperadrenergic states resulting in the aforementioned symptoms [12].

Box jellyfish in Thailand are usually found on days of good weather, when the seas are calm. They are found in shallow water where there are no reefs, and usually in the evening. A study conducted by Sucharitakul et al. [13], found that the most common species of Chirodropid found in Thailand is Chiropsoides buitendijki, but this type of jellyfish do not cause severe symptoms, according to Thaikruea and Siriariyaporn [7]. The lethal Chironex is found both in the Gulf of Thailand and the Andaman Sea [11], being most common in Surat Thani province, usually found between the months of June to December, the highest being in August. They are also found at the Eastern Gulf of Thailand (Trat province) between December and May. For the Andaman Sea, they are most common during October to January. The timings coincide with the high season of tourism in these provinces, which is why it is an important public concern (Figs. 2, 3).

\section{BLUE BOTTLE/PORTUGUESE MAN-OF-WAR}

Physalia spp. are found in all hot and temperate climate waters [1]. Physalia physalis (Portuguese man-of-war) have several tentacles and can cause systemic symptoms. There have been three reported deaths from this species in the United States. Physalia are colonies of siphonophores, with a gas-filled float keeping the colony on the surface and allows for wind-assisted travel. Hence, they are usually found floating. Their floats and tentacles have a blue-purplish colour and tentacles of the Physalia physalis can reach up to $30 \mathrm{~m}$ in length, whereas the smaller Physalia utriculus (bluebottle

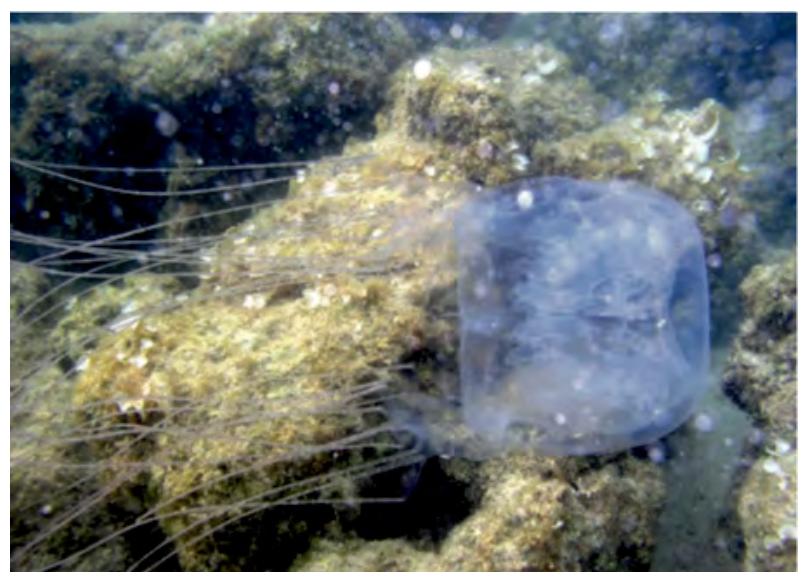

Figure 2. Chironex spp. found in Samui, Thailand (copyrighted Sakanan Plathong)

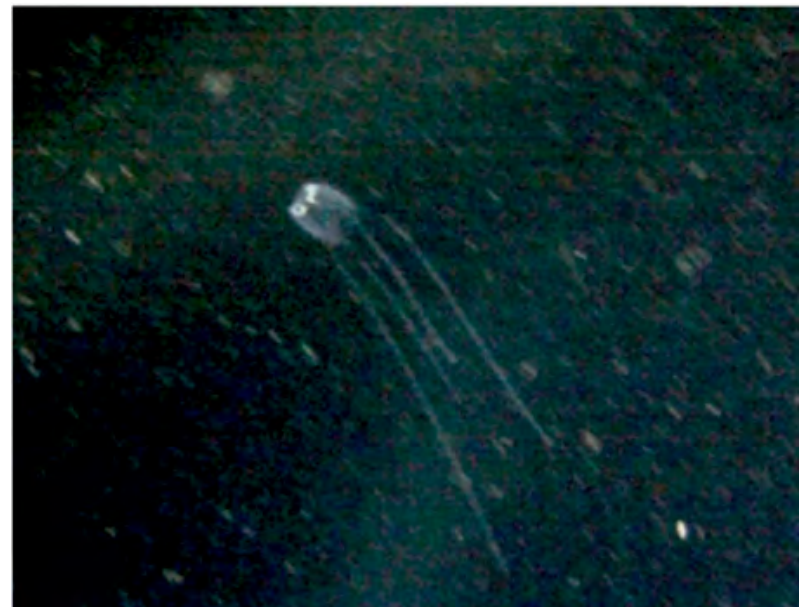

Figure 3. Single tentacle box jellyfish, Surin Islands (copyrighted Thanawat Supanitayanon)

jellyfish) have one main tentacle reaching up to $3 \mathrm{~m}$ [8]. Their nematocysts are arranged into stinging buttons and when stung, causes a linear "string of beans" lesion. In vitro studies have shown that their venom causes exocytosis of mast cell granules and release of histamine. Studies have also shown that the venom can stimulate smooth muscles, thus affecting the cardiovascular system. The pain is sharp and violent, which usually subsides within $24 \mathrm{~h}$. Physalia physalis can cause headaches, nausea, vomiting, abdominal pain, and unconsciousness. Physalia utriculus have been reported to cause a hypersensitivity reaction, though it is rare. Physalia utriculus have been reported to be found in Thailand in recent years, and do not cause severe symptoms, but still required medical care in some victims (Fig. 4).

There are other types of toxic jellyfish that are found in Thai waters but do not cause severe systemic symptoms. Some of these are Chiropsoides buitendijki, Pelagia spp., Chrysaora spp., and Lobonema smithii [7]. 

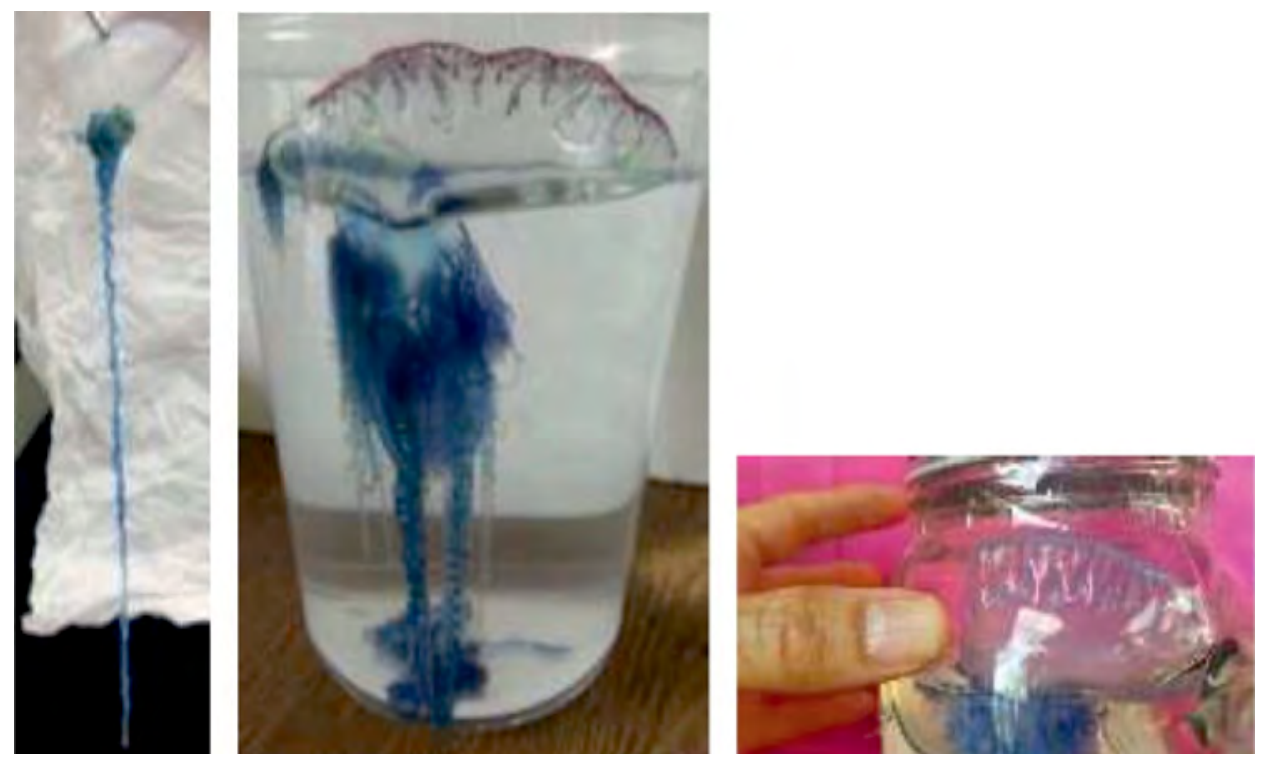

Figure 4. Physalia spp. (copyrighted Lakkana Thaikruea)

\section{TREATMENT AND MANAGEMENT}

First aid is an important aspect in managing jellyfish envenomation, helping to reduce morbidity and mortality of cases. After removing the victim from the water, it must be assured that the victim has adequate respiration and blood circulation by performing basic life support. In life-threatening stings, calling for help or ambulance (in Thailand 1669) is a must [11]. The wound should not be rubbed, and the stung area must be immediately rinsed with vinegar for at least $30 \mathrm{~s}$ to deactivate undischarged nematocysts. Fresh water should not be used as it stimulates nematocysts discharge by osmosis. Seawater should be used if vinegar is not available. Vinegar-treated tentacles should be removed if they are still adhered to the skin, preferably with tweezers, or they could be removed with bare hands, but the rescuers fingers must be carefully rinsed off afterwards to prevent secondary stings [2]. However, in the case of blue bottle jellyfish stings, the use of vinegar as a first aid treatment is still controversial. Some reports have shown more nematocysts firing after vinegar. Thaikruea et al. [13] has reported the testing vinegar and seawater on a live blue bottle found on Koh Lanta, Krabi, and found no significant firing from undischarged nematocysts from both vinegar- and seawater-treated tentacles. However, this still needs more research and laboratory testing. Therefore, it is best to use seawater in cases of blue bottle stings. In Thailand, the plant Ipomoea biloba has been used by locals to treat jellyfish stings as well, though the efficacy of this has never been proven.

After tentacle removal, the next step in controlling the victim's pain is by hot water immersion. According to a review by Li et al. [14] there were a few number of trials conducted to compare pain relief from hot water immersion and icepacks. Hot water immersion was found to be clinically significant in alleviating pain when compared to ice packs in the case of Physalia stings. As for Chironex stings, cold compresses are recommended by the Australian Resuscitation Council [15]. There is limited data of clinical evidence for the use of $\mathrm{C}$. fleckeri anti-venom in other species, and it is not available in Thailand [16].

Advanced and hospital-based management is required especially in the case of Irukandji or Irukandji-like syndrome, since the symptoms are often delayed. It is advisable to transport the victim to a hospital [17]. Intravenous magnesium sulphate is the most effective current therapy since this will reduce hypertension and pain associated with this syndrome [12]. Nitrates such as nitroglycerin or nicardipine can also be given in hypertensive emergency cases [11]. Pain is controlled with fentanyl or morphine and benzodiazepines though it should be given cautiously due to risks such as respiratory depression [12]. Pain in mild or moderate cases can be controlled with oral acetaminophen or nonsteroidal anti-inflammatory drugs $[7,18]$. Antihistamine combination of $\mathrm{H} 1$ - and $\mathrm{H} 2$-receptor antagonists may be given to reduce the histamine overload from Irukandji syndrome, not because of anaphylaxis, since true anaphylaxis from jellyfish are extremely rare [19]. Misdiagnosis is possible due to the fact that box jellyfish information and management is not included in the Thai medical school curriculum, though some emergency medicine training programs have started to include this in their training [6].

\section{PREVENTION}

The most important method in prevention of life-threatening stings and injuries include awareness of the problem 
and prevention of envenomation [17, 20]. Since the toxic jellyfish network has been setup in Thailand, more concerned authorities and stakeholders are taking into action on prevention programmes. Vinegar poles and stinger nets have been installed in many high-risk areas. Multi-language appropriate signage that includes warning of possible jellyfish encounters, wearing protective Lycra clothing covering the entire body and limbs, and first aid management had been setup in some areas, but this is still difficult due to the sensitive issue of tourism [21]. Brochures should also be distributed to hotel and tour operators, and available in airports, train stations, and bus stations. Moreover, educational programmes including basic knowledge and recognition of jellyfish, first aid management has been given to medical staff, first responders, and volunteers in high risk areas [6]. This educational program should still be an ongoing programme, not limited to medical staff or first responders, but expanded to the local population such as school children and teachers, since bystanders are most likely to be the first responders in helping the victims.

\section{REFERENCES}

1. Cegolon L, Heymann WC, Lange JH, et al. Jellyfish stings and their management: a review. Mar Drugs. 2013; 11(2): 523-550, doi:10.3390/md11020523, indexed in Pubmed: 23434796.

2. Lakkis NA, Maalouf GJ, Mahmassani DM. Jellyfish stings: a practical approach. Wilderness Environ Med. 2015; 26(3): 422-429, doi:10.1016/j.wem.2015.01.003, indexed in Pubmed: 25935311.

3. Tibballs J, Li R, Tibballs HA, et al. Australian carybdeid jellyfish causing "Irukandji syndrome". Toxicon. 2012; 59(6): 617-625, doi:10.1016/j.toxicon.2012.01.006, indexed in Pubmed: 22361384.

4. Gershwin La, Richardson AJ, Winkel KD, et al. Biology and ecology of Irukandji jellyfish (Cnidaria: Cubozoa). Adv Mar Biol. 2013; 66: 1-85, doi:10.1016/B978-0-12-408096-6.00001-8, indexed in Pubmed: 24182899.

5. Carrette TJ, Underwood AH, Seymour JE. Irukandji syndrome: a widely misunderstood and poorly researched tropical marine envenoming. Diving Hyperb Med. 2012; 42(4): 214-223, indexed in Pubmed: 23258458.

6. Thaikruea L, Siriariyaporn P. The magnitude of severe box jellyfish cases on Koh Samui and Koh Pha-ngan in the Gulf of Thailand. BMC Res Notes. 2016; 9: 108, doi: 10.1186/s13104-016-1931-8, indexed in Pubmed: 26888067.

7. Thaikruea L, Siriarayaporn P. Injuries and deaths caused by toxic jellyfish: Surveillance, prevention, and treatment. [Internet]. Chiang Mai: Faculty of Medicine of Chiang Mai University; 2018. http:// oknation.nationtv.tv/blog/lakthai (cited 2018 Nov 1).
8. Tibballs J. Australian venomous jellyfish, envenomation syndromes, toxins and therapy. Toxicon. 2006; 48(7): 830-859, doi:10.1016/j. toxicon.2006.07.020, indexed in Pubmed: 16928389.

9. Thaikruea L, Siriariyaporn P. Severe dermatonecrotic toxin and wound complications associated with box jellyfish stings 2008-2013. J Wound Ostomy Continence Nurs. 2015; 42(6): 599-604, doi: 10.1097/WON.0000000000000190, indexed in Pubmed: 26528872.

10. Thaikruea L, Siriariyaporn P, Wutthanarungsan R, et al. Review of fatal and severe cases of box jellyfish envenomation in Thailand. Asia Pac J Public Health. 2015; 27(2): NP1639-NP1651, doi: 10.1177/1010539512448210, indexed in Pubmed: 22743852.

11. Chaiyakul T. Jellyfish Envenomation in Thailand: Field and Prehospital Management. R Thai Navy Med J. ; 44: 199-206.

12. Yanagihara AA, Wilcox C, Smith J, Surrett GW. Cubozoan envenomations: clinical features, pathophysiology and management. In: Goffredo S, Dubinsky Z, editors. The Cnidaria, past, recent and future: The world of medusa and her sisters. Springer, Cham 2016: 637-652.

13. Sucharitakul P, Chomdej S, Achalawitkun T, et al. Chirodropid box jellyfish in the Gulf of Thailand. Marine Biodiversity. 2018, doi: 10.1007/s12526-018-0887-4.

14. Li L, McGee RG, Isbister G, et al. Interventions for the symptoms and signs resulting from jellyfish stings. Cochrane Database Syst Rev. 2013(12): CD009688, doi: 10.1002/14651858.CD009688. pub2, indexed in Pubmed: 24318773.

15. Australian Resuscitation Council. Guideline 9.4.5 Envenomationjellyfish stings. [Internet]. 2010 . https://resus.org.au/guidelines/ ([cited 2018 Nov 1).

16. Suntrarachun S, Roselieb M, Wilde $H$, et al. A fatal jellyfish encounter in the Gulf of Siam. J Travel Med. 2001; 8(3): 150-151, indexed in Pubmed:11468120.

17. de Pender AMG, Winkel KD, Ligthelm RJ. A probable case of Irukandji syndrome in Thailand. J Travel Med. 2006; 13(4): 240-243, doi: 10.1111/j.1708-8305.2006.00041.x, indexed in Pubmed: 16884407.

18. Burnett J. Medical aspects of jellyfish envenomation: pathogenesis, case reporting and therapy. Jellyfish Blooms: Ecological and Societal Importance. 2001: 1-9, doi: 10.1007/978-94-010-0722-1_1.

19. Lippmann JM, Fenner PJ, Winkel K, et al. Fatal and severe box jellyfish stings, including Irukandji stings, in Malaysia, 20002010. J Travel Med. 2011; 18(4): 275-281, doi: 10.1111/j. 1708-8305.2011.00531.x, indexed in Pubmed: 21722240.

20. Fenner P. Awareness, Prevention and Treatment of world-wide marine stings and bites. [Internet]. 1997.https://www.ilsf.org/ sites/ilsf.org/files/filefield/treatmentofmarinestings.pdf (cited 2018 Nov 1$).$

21. Fenner P, Lippmann J, Gershwin L. Fatal and Nonfatal Severe Jellyfish Stings in Thai Waters. J Travel Med. 2010; 17(2): 133-138, doi: 10.1111/j.1708-8305.2009.00390.x. 